\title{
Family Environment and Pediatric Major Depressive Disorder
}

\author{
Kelin M. Ogburn ${ }^{a}$ Marsal Sanches $^{d}$ Douglas E. Williamson ${ }^{a, b}$ \\ Sheila C. Caetano ${ }^{a, e}$ Rene L. Olvera ${ }^{a}$ Steven Pliszka ${ }^{a}$ John P. Hatcha, c \\ Jair C. Soares ${ }^{d}$
}

Departments of a Psychiatry, ${ }^{b}$ Epidemiology and Biostatistics, and ${ }^{c}$ Orthodontics, The University of Texas Health Science Center at San Antonio, San Antonio, Tex., and d UT Center of Excellence on Mood Disorders, Department of Psychiatry and Behavioral Sciences, The University of Texas Health Science Center at Houston, Houston, Tex., USA;

e Department of Psychiatry, University of Sao Paulo School of Medicine, Sao Paulo, Brazil

\section{Key Words}

Family environment - Major depression • Children •

Adolescents

\begin{abstract}
Background: The risks for depression broadly include biological and environmental factors. Furthermore, having a family member suffering from major depression is also likely to have consequences for the family environment. Further research aimed at understanding the effects of having a child with major depression on family interaction patterns is warranted. Methods: We studied 31 families with an 8- to 17-year-old child (mean age \pm SD $=12.9 \pm 2.7$ years) who met the DSM-IV criteria for major depressive disorder (MDD) and 34 families with no mentally ill children (mean age \pm $\mathrm{SD}=12.6 \pm 2.9$ years) or parents. Children and their parents were assessed with the K-SADS-PL (Kiddie Schedule for Affective Disorders and Schizophrenia - Present and Lifetime Version) interview. Parents completed the Moos Family Environment Scale (FES) to assess their perceptions of current family functioning. Data were analyzed using the nonparametric Wilcoxon-Mann-Whitney test. Results: Families of MDD children showed significantly different patterns of family functioning on FES subscales representing relation-
\end{abstract}

ships and personal growth dimensions. The families with MDD children showed higher levels of conflict ( $p<0.001)$ and lower levels of cohesion ( $p<0.001)$, expressiveness $(p=$ 0.003 ) and active-recreational orientation ( $p=0.02)$ compared to the families without mentally ill children. Conclusion: Families with MDD children show a lower degree of commitment, provide less support to one another, provide less encouragement to express feelings and have more conflicts compared to families with no mentally ill children or parents. Interventions aimed at improving family dynamics may be beneficial to MDD children and their families.

Copyright $\odot 2010$ S. Karger AG, Basel

\section{Introduction}

Emotional and behavioral disorders are associated with both genetic and environmental factors [1-4]. General family functioning includes factors like cohesion, harmony and the ability to deal with conflicting prob-

A preliminary version of this work was previously presented at the Society of Biological Psychiatry Annual Meeting in May 2007, and the abstract was published in Biology Psychiatry (2007;61:94S-95S).

\section{KARGER}

Fax +4161306 1234

E-Mail karger@karger.ch

www.karger.com
(C) 2010 S. Karger AG, Basel

0254-4962/10/0435-0312\$26.00/0

Accessible online at:

www.karger.com/psp
Jair C. Soares, MD

UT Center of Excellence on Mood Disorders

Department of Psychiatry and Behavioral Sciences, UT Houston Medical School

1941 East Road, Houston, TX 77054 (USA)

Tel. +1 713486 2507, Fax +1 713486 2553, E-Mail jair.c.soares@ uth.tmc.edu 
lems. These characteristics can have a profound impact on offspring's experiences and life trajectories, playing an important role in the emotional development during childhood [5]. Thus, the family environment may represent a critical early contribution to the risk for mood disorders $[6,7]$.

Further, certain interpersonal characteristics such as high levels of 'expressed emotion' (described as criticism, hostility or emotional overinvolvement of caregivers toward a family member suffering from a psychiatric illness) can negatively influence the treatment and prognosis of several psychiatric disorders, including unipolar depression and bipolar disorder [8-10]. Depressive children who attempted suicide described their families as more stressful, less supportive, and with lower control, less cohesiveness and higher conflict than children with nonsuicidal depression [11]. There is also evidence of an association between a negative family environment and a higher suicide risk among children and adolescents with bipolar disorder [12].

On the other hand, it is known that having a family member with major depressive disorder (MDD) may represent a significant burden and possibly result in negative effects on family functioning [13-16]. Impairment in family function has been demonstrated among adult patients with MDD and bipolar disorder, and depressed children show significantly impaired psychosocial relationships during the depressive episode $[17,18]$. Most importantly, many of these impairments may not improve completely, even after a sustained recovery from the depressive episode $[18,19]$. In other words, the relationship between an impaired family functioning and the diagnosis of a mood disorder in children most likely follows a bidirectional pathway, where family functioning may not only be considered a contributing factor to the disorder but may also be negatively influenced by it [20].

Moreover, available evidence suggests that parental psychopathology seems to influence the family environment and its relationship with mood disorders in children and adolescents $[20,21]$. Families with a depressed parent tend to be less supportive, less cohesive, and have lower levels of independence and social integration as well as less organization, with negative consequences for the children [22-25]. Similar findings have been described among families with a bipolar parent [26]. Therefore, while the children of parents suffering from mood disorders are at increased risk for mental disorders because of an inherited vulnerability, they are also exposed to detrimental psychosocial influences because they are raised by a parent with a potentially severe and chronic mental disorder.

The objective of our study was to assess the family environment of depressed children and adolescents, compared to the families of healthy controls. Based on previous literature, we hypothesized that the family environment of depressed children would be characterized by poorer functioning than the environment of healthy ones.

\section{Participants and Methods}

\section{Participants}

Thirty-one children and adolescents aged 8-17 years who met the DSM-IV criteria for MDD [27] were included in the study. Thirty-four healthy children and adolescents were matched to the depressive sample by age and gender and served as a comparison sample. We recruited subjects who responded to radio advertisements and flyers placed in the community and at hospitals and clinics in the South Texas Medical Center area. A psychiatrist interviewed the children and at least one parent using the Kiddie Schedule for Affective Disorders and Schizophrenia - Present and Lifetime Version (K-SADS-PL) [28], the Children's Depression Rating Scale (CDRS) [29], the Hamilton Scale for Depression (HAM-D) [30], and the Children Global Assessment Scale (CGAS) [31] to assess the psychiatric diagnosis and the intensity of depressive symptoms. The interrater reliability standard for diagnosis was $100 \%$ scoring agreement with a board-certified child psychiatrist on the K-SADS-PL over at least 5 interviews. Exclusion criteria for all subjects were presence of neurological disorders, head trauma, alcohol/substance abuse or dependence within the 6 months preceding study entry or significant medical disease. Healthy comparison children did not meet DSM-IV criteria for any axis I psychiatric disorder according to the K-SADS-PL, and also did not have any lifetime axis I psychiatric disorder among their first-degree relatives.

Family Environment Scale

The Family Environment Scale (FES) [32] is a 90-item inventory with 10 subscales that measure the social-environmental characteristics of families. The 10 FES subscales assess 3 underlying domains, namely 'relationship', 'personal growth or goal orientation' and 'system maintenance'. The 'relationship' dimension is measured by the 'cohesion', 'expressiveness', and 'conflict' subscales. These subscales assess the degree of commitment, help and support that family members provide for one another, the extent to which family members are encouraged to act openly and to express their feelings directly and the amount of openly expressed anger, aggression and conflict among family members.

The 'personal growth' or 'goal orientation' dimension is measured by the 'independence', 'achievement orientation', 'intellectual-cultural orientation', 'active-recreational orientation' and 'moral-religious emphasis' subscales. These subscales assess the extent to which family members are assertive, self-sufficient and make their own decisions, the extent to which activities (such as 
Table 1. Demographic characteristics of patients with MDD ( $\mathrm{n}=$ 31) compared to healthy controls $(n=34)$

\begin{tabular}{llcc}
\hline & $\begin{array}{l}\text { MDD } \\
\text { patients, } \mathrm{n}\end{array}$ & HC, $\mathrm{n}$ & $\mathrm{p}$ \\
\hline Ethnicity & & & 0.04 \\
$\quad$ Black & $2(7)$ & $5(14)$ & \\
$\quad$ Hispanic & $12(39)$ & $21(62)$ & \\
$\quad$ White & $16(51)$ & $8(24)$ & \\
$\quad 1(3)$ & 0 & \\
Others & $16(52)$ & $17(50)$ & n.s. \\
$\begin{array}{l}\text { Age (meander } \pm \text { SD), years } \\
\text { SES Hollingshead Scale score } \\
\quad \text { (mean } \pm \text { SD) }\end{array}$ & $12.9 \pm 2.7$ & $12.6 \pm 2.9$ & n.s. \\
\hline
\end{tabular}

$\mathrm{HC}=$ Healthy controls; SES = socioeconomic status. Figures in parentheses are percentages.

school and work) are cast into an achievement-orientated or competitive framework, the degree of interest in political, social, intellectual and cultural activities, the extent of participation in social and recreational activities, and the degree of emphasis on ethical and religious issues and values.

The 'system maintenance' dimension is measured by two subscales: 'organization' and 'control'. Organization is the degree of importance assigned to clear organization and structure in planning family activities and responsibilities, and control is how frequently set rules and procedures are used to run family life.

The validity and reliability of the FES have been previously demonstrated [32]. We used the real form (Form R) administered to one of the parents and not to the children in order to avoid possible bias on the patients' perceptions of their family environment due to their depressive state [33].

\section{Statistical Analysis}

Data analysis was performed using SPSS for Windows software version 14.0 (SPSS, Inc., Chicago, Ill., USA). We used the nonparametric Wilcoxon-Mann-Whitney procedure with exact significance testing to examine the hypothesis that the FES scores of depressed and healthy comparison families were similar. We defined two-sided statistical significance as $\mathrm{p}<0.05$ after application of the Bonferroni procedure to correct for analysis of the 10 FES subscales. In addition, we performed exploratory analyses utilizing Spearman correlations to assess the association between the FES subscale scores and age at depressive disorder onset, length of illness, and the CDRS, HAM-D and CGAS scores. The Wilcoxon-Mann-Whitney test was also used to compare the FES subscale scores as a function of the presence of an acute episode of depression versus MDD in remission and the presence versus absence of comorbidities.

This study was approved by the UTHSCSA Institutional Review Board. Written informed consent was obtained from parents and written assent was obtained from the children after a detailed explanation of the study requirements was provided.

\section{Results}

\section{Demographic Characteristics}

There were no statistically significant differences in age, gender or socioeconomic status between the MDD and the comparison samples (table 1). There was a higher proportion of white subjects in the MDD group (51\%), while the healthy comparison group contained more Hispanic subjects (62\%). The families with MDD children and the control families mostly belonged to class III (Hollingshead Scale) [34] with mean \pm SD Hollingshead Scale scores of $44.2 \pm 14.1$ and $46.7 \pm 13.3$, respectively $(\mathrm{p}=\mathrm{n} . \mathrm{s}$.), reflecting that parents on average had received partial college education and worked as technicians or sales workers or owned small businesses.

\section{Clinical Characteristics of MDD Patients}

The mean age at onset of MDD was $10.0 \pm 2.8$ years (table 2). There was a high prevalence of psychiatric comorbidities (80\%) among the MDD subjects, most of them with externalizing disorders (45\%) [oppositional defiant disorder, attention deficit and hyperactivity disorder (ADHD)] and anxiety disorders (39\%) (generalized anxiety disorder, separation anxiety, panic disorder, social phobia and obsessive-compulsive disorder). There was also a high prevalence (90\%) of psychiatric disorders among the first-degree relatives of the MDD subjects. Fifteen $(48 \%)$ children had a parent with MDD and 9 (29\%) had a parent diagnosed with bipolar disorder. Thirteen (42\%) children had a grandparent with MDD and $2(6 \%)$ had a grandparent with a history of bipolar disorder. Other diagnoses found among the parents were ADHD (10\%), anxiety (10\%) and alcohol and drug use disorder (29\%). Possible psychiatric morbidity among the siblings of the MDD patients was not assessed. The severity of the depressive symptoms in the MDD children ranged from low to moderate, according the scores of the CDRS, HAM-D and CGAS scales.

\section{Family Environment of Depressive and Healthy \\ Subjects}

The families with MDD subjects had mean FES scores that were significantly different from the comparison families on 4 of the 10 FES subscales (table 3 ). Significant differences occurred on all 3 subscales of the relationships dimension, where families of MDD children exhibited higher conflict and lower cohesion and expressiveness compared to comparison families with only healthy children. Families of MDD children also achieved significantly lower scores on the active-recreational orien- 
Table 2. Clinical features and psychiatric family history of the MDD patients $(\mathrm{n}=31)$

\begin{tabular}{lc}
\hline Feature & MDD subjects, $\mathrm{n}$ \\
\hline Comorbid psychiatric disorders & \\
Externalizing disorders & $14(45)$ \\
ADHD & $13(42)$ \\
ODD & $5(16)$ \\
Any anxiety disorder & $12(38.7)$ \\
GAD & $9(29)$ \\
Separation anxiety disorder & $5(16)$ \\
Social phobia & $3(9.6)$ \\
Panic disorder & $2(6.4)$ \\
Specific phobia & $2(6.4)$ \\
OCD & $1(3)$ \\
\hline
\end{tabular}

Family history of mental disorders

Any family history $28(90)$

Parent with MDD 15 (48)

Parent with bipolar disorder $9(29)$

Parent with ADHD $3(10)$

Parent with GAD $3(10)$

Parent with SUD $9(29)$

Grandparent with MDD $13(42)$

Grandparent with bipolar disorder 2 (6)

\begin{tabular}{lc}
\hline Other features & \\
Currently receiving psychiatric medications & $15(48)$ \\
History of psychiatric hospitalizations & $4(12.9)$ \\
Age of onset (mean \pm SD), years & $10.0 \pm 2.8$ \\
CDRS score (mean \pm SD) & $33.8 \pm 23.8$ \\
HAM-D score (mean \pm SD) & $11.6 \pm 6.6$ \\
CGAS score (mean \pm SD) & $62.5 \pm 12.3$
\end{tabular}

ODD = Oppositional defiant disorder; GAD = generalized anxiety disorder; OCD = obsessive-compulsive disorder; SUD = substance use disorder. Figures in parentheses are percentages. tation subscale of the personal growth dimension, and they showed a trend towards lower moral-religious emphasis compared to the comparison families. The families with MDD children did not differ from the comparison families on either of the 2 system maintenance dimension subscales which measure organization and control.

\section{Family Environment of MDD Subjects with Comorbidity}

As there was a high rate of comorbidity among the depressed with, we compared the healthy comparison families with the families of MDD children without any comorbidities $(\mathrm{n}=18)$. The same FES subscales (i.e., cohesion, expressiveness, conflict, active-recreational orientation and moral-religious orientation) were significantly different from the healthy group. We further compared the MDD children without comorbidities with the MDD children with ADHD comorbidity $(\mathrm{n}=13)$ and found no significant differences on any of the FES subscales.

\section{Family Environment of MDD Subjects as a Function \\ of Other Clinical Features of MDD}

There were no statistically significant differences between the FES scores of MDD subjects experiencing a current episode of MDD and those with MDD in remission. The FES subscales also did not differ between the families with children with a single episode of depression and the families with children with recurrent episodes of depression.

Table 3. Mean FES scores of the MDD patients $(n=31)$ compared to healthy controls $(n=34)$

\begin{tabular}{|c|c|c|c|c|c|}
\hline $\begin{array}{l}\text { FES } \\
\text { dimensions }\end{array}$ & $\begin{array}{l}\text { FES } \\
\text { subscales }\end{array}$ & $\begin{array}{l}\text { MDD patients } \\
(\text { mean } \pm S D)\end{array}$ & $\begin{array}{l}\text { Comparison subjects } \\
(\text { mean } \pm \mathrm{SD})\end{array}$ & Z scores & $\begin{array}{l}\text { Bonferroni- } \\
\text { corrected p }\end{array}$ \\
\hline \multirow[t]{3}{*}{ Relationships } & cohesion & $38.29 \pm 16.8$ & $58.76 \pm 9.2$ & -5.22 & $<0.001$ \\
\hline & expressiveness & $44.94 \pm 11.9$ & $57.03 \pm 6.9$ & -4.06 & 0.003 \\
\hline & conflict & $56.03 \pm 13.1$ & $43.41 \pm 8.2$ & -3.86 & $<0.001$ \\
\hline \multirow{5}{*}{$\begin{array}{l}\text { Personal } \\
\text { growth }\end{array}$} & independence & $47.06 \pm 10.7$ & $47.12 \pm 11.2$ & -0.16 & 1.0 \\
\hline & achievement orientation & $46.42 \pm 10.7$ & $51.71 \pm 8.4$ & -2.10 & n.s. \\
\hline & intellectual cultural orientation & $47.23 \pm 13.6$ & $54.59 \pm 10.5$ & -1.99 & n.s. \\
\hline & active-recreational orientation & $44.1 \pm 14.3$ & $55.47 \pm 7.1$ & -3.07 & 0.02 \\
\hline & moral-religious orientation & $56.00 \pm 10.4$ & $61.74 \pm 9.5$ & -2.69 & 0.07 \\
\hline \multirow{2}{*}{$\begin{array}{l}\text { System } \\
\text { maintenance }\end{array}$} & organization & $48.61 \pm 12.0$ & $51.53 \pm 12.6$ & -0.86 & n.s. \\
\hline & control & $55.87 \pm 9.4$ & $53.35 \pm 8.0$ & -0.99 & n.s. \\
\hline
\end{tabular}


We further found no significant association between any FES subscale scores and the child's age at onset of depressive disorder or the duration of illness. Spearman's $\rho$ correlations also indicated no significant correlations between the FES subscale scores and other measures of illness severity, including CGAS, HAMD, and CDRS scores.

\section{Family Environment according to Ethnicity}

We also compared the FES subscale scores of the Hispanic families $(\mathrm{n}=33)$ and the white families $(\mathrm{n}=24)$ in our total sample. Only the independence subscale, which was not different between MDD and healthy comparison subjects, was significantly different, with the white families (mean $\pm \mathrm{SD}=52.0 \pm 10.4$ ) scoring higher than the Hispanic families (mean $\pm \mathrm{SD}=43.5 \pm 10.8 ; \mathrm{Z}=-2.7$, $\mathrm{p}=0.007)$.

\section{Discussion}

We compared the functioning of families with an MDD child to control families with only healthy children and no history of mental disorders in first-degree relatives. The most pronounced differences found were related to the dimensions reflecting family relationships. The families of MDD children displayed less cohesion and expressiveness than comparison families, indicating a lack of involvement and poor communication in families of depressed subjects. Families of MDD children also demonstrated higher levels of conflict compared to the comparison families, suggesting that they express their anger toward other family members more openly and in a conflict-oriented way. The MDD families also reported lower levels of active-recreational orientation and tended towards lower moral-religious orientation than the families of the comparison children.

These results are comparable to previous studies with families of children with mood disorders. In one of the first studies to focus on this issue, Puig-Antich et al. [17] described a significant impairment in the interpersonal relationships domain in the families of depressive children, especially in the child-parent and child-siblings relationships. Studying hospitalized children with MDD and healthy controls, another group found associations between depression in children and lack of familial cohesiveness and emotional bonding [35]. With respect to bipolar children, a third group described higher levels of familial conflict associated with the diagnosis of bipolar disorder in children [21]. Finally, our group reported lower levels of cohesion, expressiveness, intellectual-cultural orientation and active-recreational orientation, as well as higher levels of conflict, among families of bipolar children compared to controls [36].

Further, our results did not show any significant differences between families where the child was experiencing an acute episode of depression or was in remission. Likewise, no differences were found between families where the child had a single depressive episode or recurrent MDD. Finally, there was no association between measures of family functioning and the severity of the acute episode of depression in the children. This suggests that our findings regarding family functioning may not merely reflect the child's current mood state. This inference is in consonance with findings of longitudinal studies, which point to the persistence of the impairment in family function even after the patient's recovery from the mood episode $[18,19]$.

Our study has some methodological limitations that have to be addressed. First, our sample of children with MDD had a high prevalence of anxiety disorders and ADHD. The presence of an externalizing disorder, like ADHD, could be a source of increased conflict, arguments and lower levels of cohesion between the family members. However, we compared the families of MDD children with comorbidities with the families of MDD children without comorbidities, and did not find significant differences between them on any of the FES subscales. Although the sample size available for this subgroups analysis was limited, this suggests that the presence of a co-occurring, chronic psychiatric conduct disorder does not wholly account for the association we found between impaired family functioning and pediatric MDD. Further, when we compared the families of MDD children without comorbidities with the families of healthy children, the results found were similar to those obtained when the entire group of MDD children was included in the analysis.

Second, data on family functioning were intentionally collected from the parents rather than from the children themselves to minimize possible bias due to the child's MDD. However, many of the parents of MDD children also had psychiatric disorders, and we cannot rule out the possibility that this may have affected their perceptions of their family functioning.

An additional issue to be considered is the slightly higher proportion of Hispanic families in the control group. Even though cultural issues can undoubtedly affect family functioning, it is unlikely that such a difference influenced our results, since the Hispanic and white families differed only on the independence subscale, and 
no differences were found between the MDD families and control families on that subscale.

Finally, our study design cannot determine whether the presence of a child with MDD disrupts the family or whether a less favorable family environment is a risk factor for childhood MDD. Both possibilities are plausible, or MDD and a disordered family environment may be connected by a third not yet identified variable. Answers to these questions must await the performance of longitudinal controlled studies that can isolate the effects of potentially confounding variables such as parental and sibling mental health and comorbid psychiatric conditions.

In summary, our findings add to the body of literature that indicates that having a child with MDD is associated with a less favorable family environment, pointing out the need for future work that will further elucidate the nature of this relationship. Furthermore, they reinforce the importance and the need for research focusing on family interventions and family involvement in the treatment of children and adolescents with mood disorders [10, 37].

\section{Acknowledgments}

This work was partly supported by MH69774 (Dr. Soares), RR020571 (Dr. Soares), M01-RR-01346 (UTHSCSA GCRC), the Krus Endowed Chair in Psychiatry (Dr. Soares), the Dielmann Endowed Chair of Genetic and Environmental Risk (Dr. Williamson), and the Capes Foundation - Brazil (Dr. Caetano).

\section{Conflict of Interest}

Dr. Olvera is in the speaker's bureau for McNeil Pediatrics, Janssen Pharmaceuticals, Shire Pharmaceuticals, and AstraZeneca. Dr. Soares is a consultant for Organon and Shire Pharmaceuticals, has research grants from Pfizer and GSK, and is in the speaker's bureau for Lilly and AstraZeneca. Dr. Sanches has been in the speaker's bureau for AstraZeneca.

\section{References}

1 Lapalme M, Hodgins S, LaRoche C: Children of parents with bipolar disorder: a metaanalysis of risk for mental disorders. Can J Psychiatry 1997;42:623-631.

$\checkmark 2$ Williamson DE, Birmaher B, Frank E, Anderson BP, Matty MK, Kupfer DJ: Nature of life events and difficulties in depressed adolescents. J Am Acad Child Adolesc Psychiatry 1998;37:1049-1057.

-3 Goodyer IM, Herbert J, Tamplin A, Altham PM: First-episode major depression in adolescents. Affective, cognitive and endocrine characteristics of risk status and predictors of onset. Br J Psychiatry 2000;176:142-149.

4 Goodyer IM, Kolvin I, Gatzanis S: The impact of recent undesirable life events on psychiatric disorders in childhood and adolescence. Br J Psychiatry 1987;151:179-184.

5 Cuffe SP, McKeown RE, Addy CL, Garrison CZ: Family and psychosocial risk factors in a longitudinal epidemiological study of adolescents. J Am Acad Child Adolesc Psychiatry 2005;44:121-129.

-6 Althoff RR, Faraone SV, Rettew DC, Morley CP, Hudziak JJ: Family, twin, adoption, and molecular genetic studies of juvenile bipolar disorder. Bipolar Disord 2005;7:598-609.

7 Yap MB, Allen NB, Sheeber L: Using an emotion regulation framework to understand the role of temperament and family processes in risk for adolescent depressive disorders. Clin Child Fam Psychol Rev 2007;10:180-196.
8 Kim EY, Miklowitz DJ: Expressed emotion as a predictor of outcome among bipolar patients undergoing family therapy. J Affect Disord 2004;82:343-352.

\$ Johnson L, Lundstrom O, Aberg-Wistedt A, Mathe AA: Social support in bipolar disorder: its relevance to remission and relapse. Bipolar Disord 2003;5:129-137.

-10 Miklowitz DJ, Axelson DA, George EL, Taylor DO, Schneck CD, Sullivan AE, et al: Expressed emotion moderates the effects of family-focused treatment for bipolar adolescents. J Am Acad Child Adolesc Psychiatry 2009;48:643-651.

-11 Asarnow JR, Carlson GA, Guthrie D: Coping strategies, self-perceptions, hopelessness, and perceived family environments in depressed and suicidal children. J Consult Clin Psychol 1987;55:361-366.

12 Goldstein TR, Birmaher B, Axelson D, Goldstein BI, Gill MK, Esposito-Smythers C, et al: Family environment and suicidal ideation among bipolar youth. Arch Suicide Res 2009; 13:378-388.

13 Saeki T, Asukai N, Miyake Y, Miguchi M, Yamawaki S: Characteristics of family functioning in patients with endogenous monopolar depression. Hiroshima J Med Sci 2002; 51:55-62.

14 Robertson HA, Kutcher SP, Bird D, Grasswick L: Impact of early onset bipolar disorder on family functioning: adolescents' perceptions of family dynamics, communication, and problems. J Affect Disord 2001;66:2537.
15 Goossens PJ, Van Wijngaarden B, Knoppertvan der Klein EA, Van Achterberg T: Family caregiving in bipolar disorder: caregiver consequences, caregiver coping styles, and caregiver distress. Int J Soc Psychiatry 2008; 54:303-316.

16 Magliano L, Orrico A, Fiorillo A, Del Vecchio H, Castiello G, Malangone C, et al: Family burden in bipolar disorders: results from the Italian Mood Disorders Study (IMDS). Epidemiol Psichiatr Soc 2009;18:137-146.

-17 Puig-Antich J, Lukens E, Davies M, Goetz D, Brennan-Quattrock J, Todak G: Psychosocial functioning in prepubertal major depressive disorders. 1. Interpersonal relationships during the depressive episode. Arch Gen Psychiatry 1985;42:500-507.

- 18 Weinstock LM, Keitner GI, Ryan CE, Solomon DA, Miller IW: Family functioning and mood disorders: a comparison between patients with major depressive disorder and bipolar I disorder. J Consult Clin Psychol 2006; 74:1192-1202.

19 Puig-Antich J, Lukens E, Davies M, Goetz D, Brennan-Quattrock J, Todak G: Psychosocial functioning in prepubertal major depressive disorders. 2. Interpersonal relationships after sustained recovery from affective episode. Arch Gen Psychiatry 1985;42:511517.

20 Restifo K, Bogels S: Family processes in the development of youth depression: translating the evidence to treatment. Clin Psychol Rev 2009;29:294-316. 
21 Du Rocher Schudlich TD, Youngstrom EA, Calabrese JR, Findling RL: The role of family functioning in bipolar disorder in families. J Abnorm Child Psychol 2008;36:849863.

22 Billings AG, Moos RH: Psychosocial processes of remission in unipolar depression: comparing depressed patients with matched community controls. J Consult Clin Psychol 1985;53:314-325.

-23 Billings AG, Moos RH: Children of parents with unipolar depression: a controlled 1-year follow-up. J Abnorm Child Psychol 1986;14: 149-166.

24 Billings AG, Moos RH: Comparisons of children of depressed and nondepressed parents: a social-environmental perspective. J Abnorm Child Psychol 1983;11:463-485.

25 Esposito-Smythers C, Birmaher B, Valeri S, Chiappetta L, Hunt J, Ryan N, et al: Child comorbidity, maternal mood disorder, and perceptions of family functioning among bipolar youth. J Am Acad Child Adolesc Psychiatry 2006;45:955-964.
6 Chang KD, Blasey C, Ketter TA, Steiner H: Family environment of children and adolescents with bipolar parents. Bipolar Disord 2001;3:73-78.

27 American Psychiatric Association: Diagnostic and Statistical Manual of Mental Disorders, ed 4 revised. Washington, American Psychiatric Association, 2000.

28 Kaufman J, Birmaher B, Brent D, Rao U, Flynn C, Moreci P, et al: Schedule for affective disorders and schizophrenia for schoolage children-present and lifetime version (KSADS-PL): initial reliability and validity data. J Am Acad Child Adolesc Psychiatry 1997;36:980-988.

29 Poznanski EO, Freeman L, Mokros HB Children's depression rating scale - revised Psychopharmacol Bull 1985;21:979-989.

30 Hamilton M: A rating scale for depression. J Neurol Neurosurg Psychiatry 1960;23:5662 .

-31 Shaffer D, Gould MS, Brasic J, Ambrosini P, Fisher P, Bird H, et al: A children's global assessment scale (CGAS). Arch Gen Psychiatry 1983;40:1228-1231.
32 Moos RH, Moos BS: Family Environmental Scale Manual. Palo Alto, Mind Garden, 2002.

33 Tamplin A, Goodyer IM, Herbert J: Family functioning and parent general health in families of adolescents with major depressive disorder. J Affect Disord 1998;48:1-13.

34 Hollingshead AB: Two Factor Index of Social Position. New Haven, Yale University Press, 1957.

35 Kashani JH, Allan WD, Dahlmeier JM, Rezvani M, Reid JC: An examination of family functioning utilizing the circumplex model in psychiatrically hospitalized children with depression. J Affect Disord 1995;35:65-73.

36 Belardinelli C, Hatch JP, Olvera RL, Fonseca M, Caetano SC, Nicoletti M, et al: Family environment patterns in families with bipolar children. J Affect Disord 2008;107:299-305.

37 Sander JB, McCarty CA: Youth depression in the family context: familial risk factors and models of treatment. Clin Child Fam Psychol Rev 2005;8:203-219. 